( С Д.А. Скуратовская ${ }^{1 *}$, М.А. Вуль $\phi^{1}$, Е.В. Кириенкова' , Н.И. Миронюк ${ }^{1,2}$, П.А. Затолокин ${ }^{1,2}$, Л.С. Литвинова ${ }^{1 *}$

'Балтийский федеральный университет имени Иммануила Канта, Калининград

²Областная клиническая больница Калининградской области, Калининград

ОБОСНОВАНИЕ. Глюкагоноподобный пептид-1 (GLP-1) стимулирует пролиферацию $\beta$-клеток, усиливает их устойчивость к апоптозу и повышает глюкозозависимую секрецию инсулина.

ЦЕЛЬ. Изучение взаимосвязи полиморфизма Leu260Phe (rs1042044) гена GLP-1R с постпрандиальной продукцией гормонов (С-пептида, инсулина, грелина, GLP-1) у больных ожирением с сахарным диабетом 2 типа (СД2).

МЕТОДЫ. Обследованы 174 пациента, 82 больных ожирением с СД2 (ИМТ=40,4ะ14,3 кг/м²) и 92 условно здоровых до-

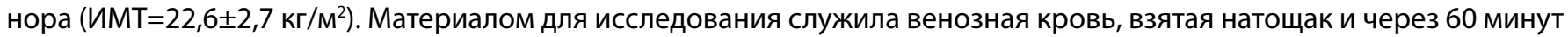
после тестового завтрака. Генотипирование проводилось методом полимеразной цепной реакции (ПЦР) с использованием наборов для определения полиморфизма (rs1042044) гена GLP-1R («Синтол») и амплификатора (CFX96 BioRad, США). Плазменный уровень гормонов оценивали методом проточной флюориметрии (Bio-Plex Protein Assay System, BioRad, США) с использованием коммерческих тест-систем (Bio-Plex Pro Human Diabetes 10-Plex Assay, BioRad, CШA). Статистический анализ и графики были получены в R Statistical Software.

РЕзУЛЬтАTЫ. Выявлено нарушение постпрандиальной продукции GLP-1 и грелина после тестового завтрака у больных ожирением с СД2. Установлено постпрандиальное повышение уровней С-пептида - 3,25 [1,83;4,16] нг/мл и инсулина - 3048 [1978;4972] нг/мл у носителей генотипа СС по сравнению с носителями генотипа СА в группе больных ожирением с СД2. У носителей генотипа СА отмечено снижение уровня С-пептида 2,21 [1,8;2,49] нг/мл и инсулина 1462 [1146;2304] нг/мл при неизменной концентрации GLP-1. Постпрандиальный уровень грелина у носителей генотипа CA полиморфизма Leu260Phe повышался до 118 [96,1;157] нг/мл по сравнению с носителями генотипа AA $98[86 ; 109]$ нг/мл.

ЗАКЛЮчЕНИЕ. Наличие генотипа CC полиморфизма Leu260Phe гена GLP- 1 рецептора взаимосвязано с повышением постпрандиальных плазменных уровней С-пептида и инсулина у больных ожирением с СД2, а генотипа СА - со снижением данных показателей и ростом содержания грелина.

КЛЮЧЕВЫЕ СЛОВА: сахарный диабет 2 типа; ожирение; полиморфизм; GLP-1R; инсулин; грелин

\title{
THE ROLE OF LEU260PHE POLYMORPHISM OF THE RECEPTOR GENE TO GLP-1 INCRETIN IN THE PATHOGENESIS OF DIABETES TYPE 2 DIABETES WITH OBESITY
}

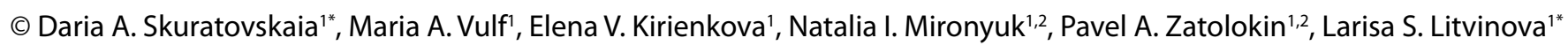

${ }^{1}$ Immanuel Kant Baltic Federal University, Kaliningrad, Russia

${ }^{2}$ Oblast Clinical Hospital of the Kaliningrad Region, Kaliningrad, Russia

BACKGRAUND: Glucagon-like peptide-1 (GLP-1) stimulates the proliferation of $\beta$-cells, enhances their resistance to apoptosis and increases glucose-dependent insulin secretion.

AIMS: Study of the relationship of Leu260Phe polymorphism (rs1042044) of the GLP-1R gene with postprandial hormone production (C-peptide, insulin, ghrelin, GLP-1) in obese patients with type 2 diabetes.

MATERIALS AND METHODS: A total of 174 patients, 82 patients with obesity with type 2 diabetes $\left(B M I=40.4 \pm 14.3 \mathrm{~kg} / \mathrm{m}^{2}\right)$ and 92 conditionally healthy donors $\left(B M I=22.6 \pm 2.7 \mathrm{~kg} / \mathrm{m}^{2}\right)$ were studied. The material for the study was venous blood taken on an empty stomach and 60 minutes after the test breakfast. Genotyping was performed by PCR using the sets for determining polymorphism (rs1042044) of the GLP-1R gene (Sintol) and the amplificator (CFX96 BioRad, USA). Plasma hormone levels were evaluated by flow fluorimetry (Bio-PlexProteinAssaySystem, Bio-Rad, USA) using commercial test systems (Bio-PlexProHumanDiabetes 10-Plex Assay, Bio-Rad, USA). Statistical analysis and graphs were obtained at R Statistical Software. 
RESULTS: A violation of postprandial production of GLP-1 and ghrelin after a test breakfast in obese patients with type 2 diabetes was found. A postprandial increase in C-peptide levels of $3.25[1.83 ; 4.16] \mathrm{ng} / \mathrm{ml}$ and insulin 3048 [1978;4972] ng/ml in carriers of the CC genotype compared with carriers of the CA genotype in the group of patients with obesity with type 2 diabetes type In carriers of the CA genotype, there was a decrease in the C-peptide level of $2.21[1.8 ; 2.49] \mathrm{ng} / \mathrm{ml}$ and insulin 1462 $[1146 ; 2304] \mathrm{ng} / \mathrm{ml}$ with a constant concentration of GLP-1. The postprandial level of ghrelin in carriers of the CA genotype of the Leu260Phe polymorphism increased to $118[96.1 ; 157] \mathrm{ng} / \mathrm{ml}$ compared to carriers of the AA 98 genotype [86; 109] $\mathrm{ng} / \mathrm{ml}$.

CONCLUSION: The presence of the CC genotype of the Leu260Phe polymorphism of the GLP-1 receptor gene is associated with an increase in postprandial plasma levels of C-peptide and insulin in obese patients with type 2 diabetes, and the CA genotype with a decrease in these indicators and an increase in ghrelin content.

KEYWORDS: type 2 diabetes; obesity; polymorphism; GLP-1R; insulin; ghrelin

Основным фактором риска развития сахарного диабета 2 типа (СД2) является абдоминальное ожирение [1]. При инсулинорезистентности (ИР) способность инсулина оказывать воздействие на ткани-мишени снижается, что способствует нарушению метаболических процессов [2]. В процессе формирования ИР принимают участие многие биологически активные вещества с системным и локальным характером действия, такие как лептин, глюкагон, грелин и инкретины.

Уровень гормона грелина с орексигенным эффектом снижается постпрандиально, этот гормон известен как «гормон голода», он участвует в регуляции энергетического баланса, в том числе в метаболизме глюкозы [3]. Напротив, инкретины секретируются постпрандиально в клетках тонкого кишечника, стимулируя глюкозозависимую секрецию инсулина [4]. Постпрандиальная продукция инсулина, стимулированная инкретинами, называется «инкретиновым эффектом» и составляет от 20\% до 50\% от общей секреции инсулина [5]. Кроме того, инкретины способствуют пролиферации $\beta$-клеток поджелудочной железы и снижают их апоптоз [6]. В частности, показаны антидиабетические эффекты инкретина GLP-1, заключающиеся в глюкозозависимой стимуляции инсулина посредством усиления транскрипции его гена [7].

GLP-1 оказывает физиологические эффекты, активируя рецептор $G L P-1 R$, принадлежащий к подклассу В семейства GPCR [8]. GLP-1R экспрессируется преимущественно в клетках островков Лангерганса, тем не менее его экспрессия наблюдается и в других тканях, в том числе в жировом депо [9]. GLP-1R способствует деполяризации мембраны $\beta$-клеток, ингибируя $\mathrm{K}^{+}$-каналы, что способствует усилению притока $\mathrm{Ca}^{2+}$ в клетки, в результате чего происходит экзоцитоз инсулина из $\beta$-клеток [8]. Таким образом, активация GLP-1R ассоциирована с важными компонентами биосинтеза и секреции инсулина [8].

Целями исследования явились поиск ассоциаций полиморфизма Leu260Phe гена GLP-1R с повышенным риском развития ожирения с СД2 и оценка взаимосвязи вариантов генотипов изучаемых полиморфизмов с сывороточными уровнями инсулина, С-пептида, GLP-1 и грелина у больных в славянской популяции.

\section{ЦЕЛЬ}

Целью исследования явилась оценка взаимосвязи полиморфных вариантов Leu260Phe (rs1042044) гена $G L P-1 R$ с постпрандиальной продукцией гормонов гастродуоденальной зоны (инсулина, С-пептида, грелина и GLP-1) у больных ожирением с СД2.

\section{МЕТОДЫ}

\section{Дизайн исследования}

В проспективное исследование случай-контроль были включены больные ожирением с СД2 и пациенты контрольной группы.

\section{Условия проведения}

Исследование проведено в Базовой лаборатории иммунологии и клеточных биотехнологий БФУ им. И. Канта. Биологический материал предоставлен Областной клинической больницей Калининградской области.

\section{Продолжительность исследования}

Биологический материал брался однократно при поступлении в стационар. В Базовой лаборатории иммунологии и клеточных технологий ведутся сбор биологического материала и формирование биобанка с 2013 г.

\section{Критерии соответствия}

В группу исследования были включены пациенты с диагнозом «ожирение и СД2». Контрольную группу составили условно здоровые доноры с нормальными биохимическими и антропометрическими показателями. Для всех участников исследования обязательным было подписание информированного согласия на участие в исследовании.

Все пациенты с ожирением, включенные в исследование, посещали школу для лиц с ожирением при Калининградской областной клинической больнице (КОКБ). Все исследуемые лица относились к восточнославянской популяции и проживали на территории Северо-Западного региона России. Пациенты с ожирением и СД2 получали консервативное лечение, которое включало изменение образа жизни: ограничение потребления пищи с высоким содержанием жиров и углеводов, физические нагрузки; прием метформина (доза 500-1500 мг в сутки) в течение года и/или более. Больные ожирением с СД2 не получали инсулинотерапию.

Критерии исключения:

- инфаркт миокарда и/или нарушения мозгового кровообращения;

- патология щитовидной железы, аутоиммунная патология, наличие инфекционных заболеваний, воспалительных очагов любой локализации, онкологических заболеваний;

- наследственные психические заболевания;

- длительный прием гиполипидемических препаратов;

- алкогольная и наркотическая зависимость. 


\section{Описание медицинского вмешательства}

Материалом исследования служила венозная кровь, взятая натощак и через 60 минут после пробного завтрака в вакуумные пробирки Vacuette с этилендиаминтетраацетатом (ЭДТА) и активатором свертывания. Пробный завтрак состоял из каши гречневой с молоком без сахара (200 г), киселя (150 г) без сахара, что соответствовало 9,1 г белков, 88,1 г углеводов, 10,6 г жиров. Общая калорийность завтрака составляла 466 ккал.

\section{Методы регистрации исходов}

На основании обследования в условиях специализированного стационара, руководствуясь критериями диагностики СД и других типов гипергликемии Всемирной организации здравоохранения (ВО3) (1999-2013), устанавливался диагноз СД2. Согласно критериям, рекомендованным ВО3 (1999, 2000), устанавливался диагноз ожирения.

Геномная ДНК выделялась из клеток крови с использованием набора QIAmpDNA MiniKit (QIAGEN GmbH, Германия). Генотип определяли методом ПЦР в режиме реального времени с использованием наборов для детекции полиморфизма Leu260Phe (rs1042044) гена GLP-1R (3АО «Синтол») на амплификаторе CFX96 (BioRad, США). Однонуклеотидный полиморфизм Leu260Phe локализован в седьмом экзоне гена $G L P-1 R$, и в диком типе генотип СС кодирует аминокислоту фенилаланин, а в мутантном (минорном) варианте генотипа АA лейцин [10].

Исследование уровня глюкозы проводили с использованием автоматического биохимического анализатоpa Furuno CA-180 (Furuno Electric Company, Япония) и тест-систем DiaSys (DiaSys Diagnostic Systems, Германия).

Для оценки чувствительности к инсулину рассчитывался индекс HOMA-IR (homeostasis model assessment insulin resistance). Индекс HOMA-IR рассчитывали по формуле: HOMA-IR = (Инс $\times$ Гл)/22,5, где Инс - инсулин плазмы натощак (мкЕд/мл); Гл - глюкоза плазмы натощак (ммоль/л).

Уровень инсулина, С-пептида, грелина и GLP-1 в плазме крови натощак и после тестового завтрака исследовали методом проточной флюориметрии (BioPlexProteinAssaySystem, Bio-Rad, США) с использованием тест-систем (Bio-PlexProHumanDiabetes 10-Plex Assay, Bio-Rad, США).

\section{Этическая экспертиза}

Всеми пациентами, принявшими участие в исследовании, было подписано добровольное информированное согласие. Разрешение на проведение исследования получено в локальном этическом комитете (протокол №2 БФУ им. И. Канта от 6 марта 2017).

\section{Статистический анализ}

Принципы расчета размера выборки: размер выборки предварительно не рассчитывался.

Методы статистического анализа данных: статистический анализ был осуществлен с использованием программы R Statistical Software (версия 3.3.1). Проверку на нормальность распределения данных проводилисприменением критерия Колмогорова-Смирнова. При соответствии нормальному закону распределения в исследуемых выборках проводили проверку гипотезы о равенстве средних выборочных величин с использованием t-критерия Стьюдента. Если распределение данных не подчинялось нормальному закону распределения, оценка отличий между выборками рассчитывалась при помощи непараметрического критерия Манна-Уитни. Наличие взаимосвязи между изучаемыми показателями проводили с применением корреляционного анализа по методу Спирмена. Различия считались достоверными при уровне значимости $p<0,05$.

\section{РЕЗУЛЬТАТЫ}

\section{Объекты (участники) исследования}

В исследование были включены 174 пациента, 82 из которых имели ожирение алиментарно-конституционального характера с абдоминальным типом локали-

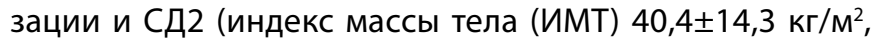

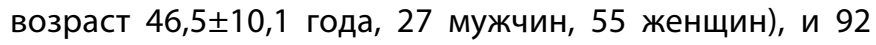
условно здоровых донора с нормальными антропометрическими и биохимическими показателями (ИМТ $22,6 \pm 2,7 \mathrm{kг} / \mathrm{M}^{2}$, возраст 37,5 $\pm 5,1$ года, 57 мужчин и 35 женщин).

\section{Основные результаты исследования}

При проведении сравнительного анализа биохимических показателей, данных о содержании гормонов в плазме крови, а также результатов генотипирования у больных ожирением с СД2 и пациентов контрольной группы, в зависимости от половых и возрастных критериев, достоверных различий нами обнаружено не было. В группе больных СД2 сывороточный уровень глюкозы составил 7,80 [6,64;10,39] ммоль/л, превышая аналогичные параметры контрольной группы - 5,23 $[4,90 ; 5,45]$ ммоль/л ( $<20,05)$ (табл. 1). Значение индекса HOMA-IR у пациентов с СД2 составило 12,4 [9,7;23,5] усл. ед., что превышало показатели контроля - 1,17 $[0,79 ; 1,65]$ усл. ед. ( $<<0,05)$. Содержание С-пептида, инсулина и глюкозы в плазме/сыворотке крови у больных ожирением с СД2 ожидаемо превосходило показатели контроля $(p<0,05)$. При этом степень постпрандиального изменения значений С-пептида и инсулина (2,35[1,83;3,7] и 2017[1356;3900] нг/мл соответственно) оказалась выше в группе больных ожирением с СД2 по сравнению с контрольными величинами $(p<0,05)$ (рис. 1).

В контрольной группе уровень GLP-1 в плазме крови повышался в 1,5 раза после тестового завтрака до 264 [248;302] нг/мл относительно значений натощак 200 [190;221] нг/мл $(p<0,05)$.

В группе контроля на фоне повышения плазменного уровня GLP-1 нами выявлено достоверно значимое снижение содержания грелина после тестового завтрака по сравнению с его уровнем натощак $(p<0,05)$ (см. рис. 1). В группе больных ожирением с СД2 содержание грелина в плазме натощак и после тестового завтрака достоверно не изменялось. При этом постпрандиальный уровень грелина в группе больных ожирением с СД2 значимо превосходил аналогичные значения в контроле $(p<0,05)$. Отмечено наличие корреляционных взаимосвязей между уровнями грелина 

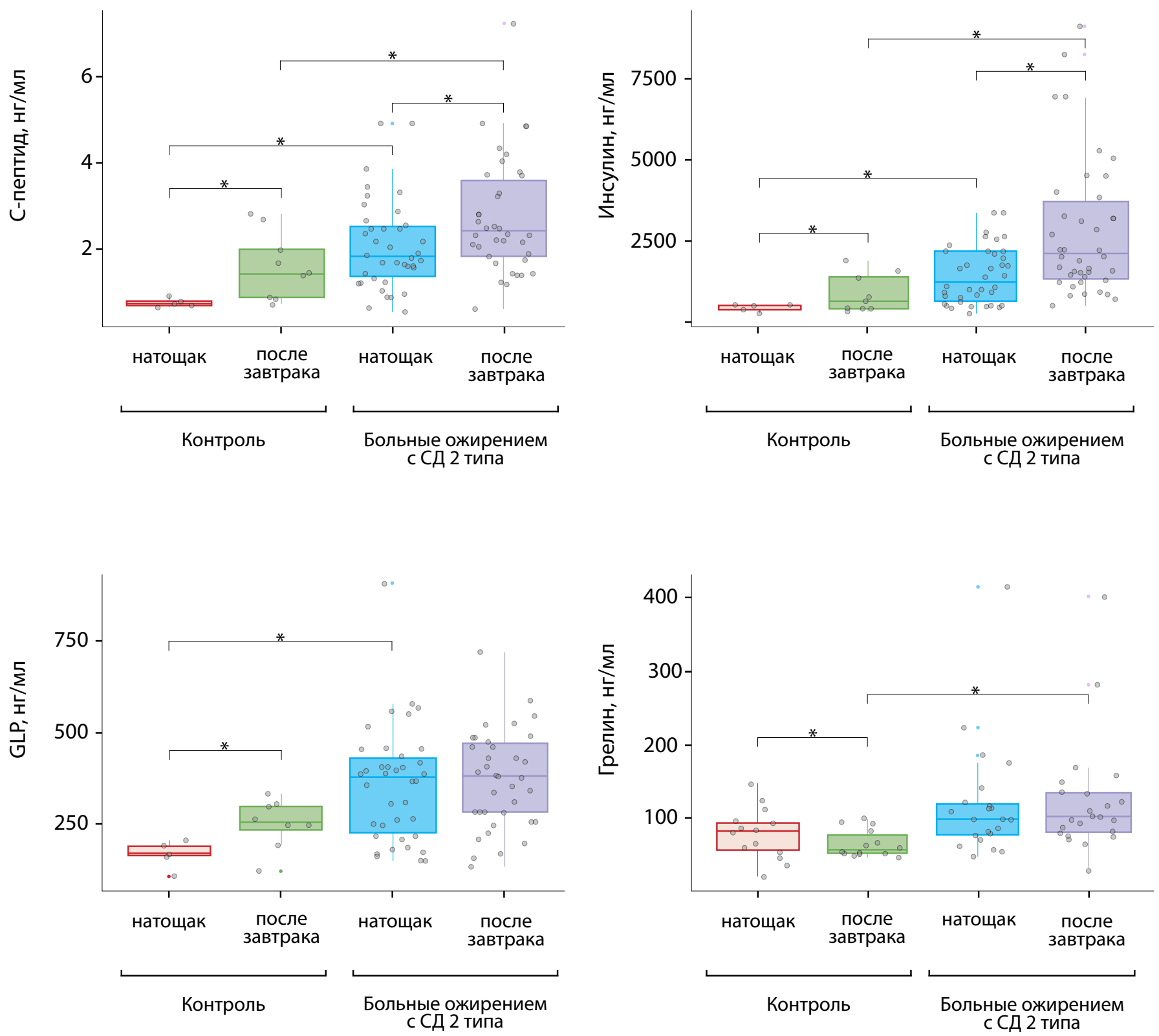

Рис. 1. Уровень гормонов желудочно-кишечного тракта (С-пептида, инсулина, грелина и GLP-1) в исследуемых группах. Данные представлены в виде медианы и интерквартильного размаха Me [Q1;Q3]

Таблица 1. Сывороточный уровень глюкозы и HOMA-IR.

\section{Сывороточный уровень глюкозы, ммоль/л}

\section{Группы}

\section{Здоровые доноры}

$(\mathrm{n}=92)$

Больные ожирением с СД 2 типа $(\mathrm{n}=82)$

Натощак

$5,23[4,90 ; 5,45]$

$7,80[6,64 ; 10,39]$

$p<0,05^{*}$
После завтрака

$$
5,5 \pm 0,8
$$

$11,03 \pm 5,23$

$\mathrm{p}<0,05^{*}$

\section{Индекс HOMA-IR, усл. ед.}

\section{Группы}

Натощак

\section{После завтрака}

\section{Здоровые доноры}

$(\mathrm{n}=92)$

$1,17[0,79 ; 1,65]$

Больные ожирением с СД 2 типа

$12,4[9,7 ; 23,5]$

$(\mathrm{n}=82)$

$p<0,05^{*}$

Примечание: * - уровень значимости определен при помощи критерия Манна-Уитни для двух независимых выборок (р<0,05). Данные представлены в виде медианы и интерквартильного размаха Me [Q1;Q3]. 


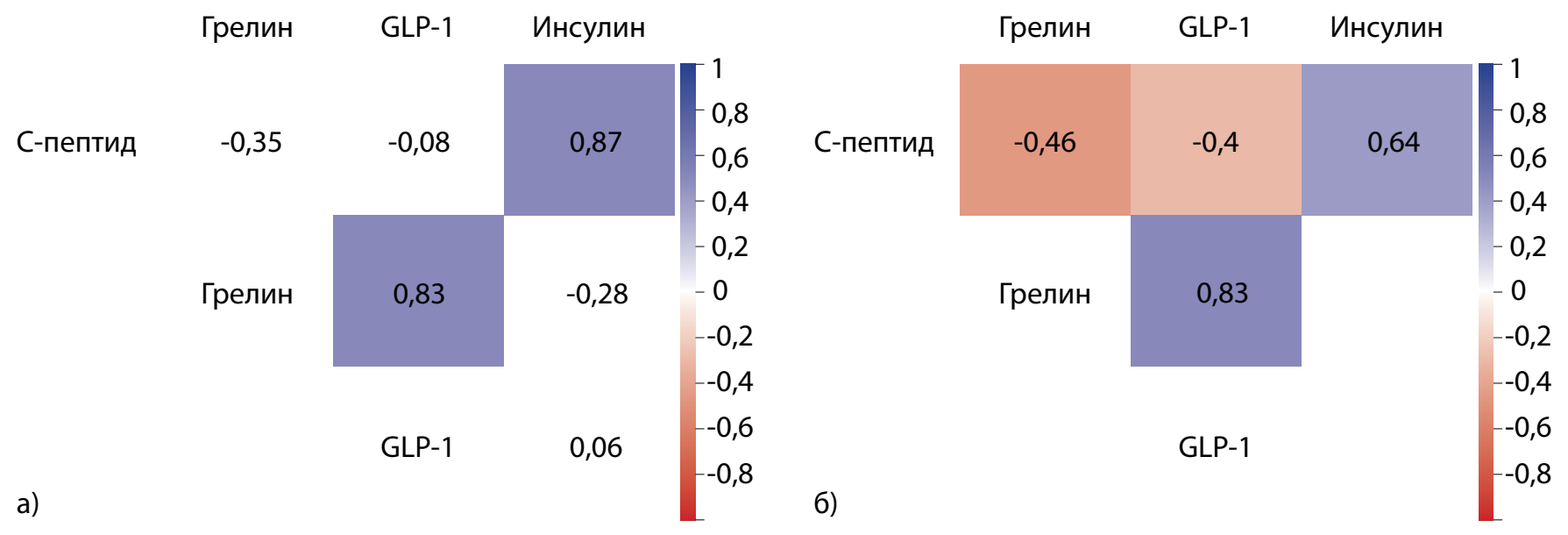

Рис. 2. Корреляционные взаимосвязи плазменного уровня C-пептида, грелина и GLP-1 и инсулина натощак (а) и после тестового завтрака (б) в группе больных ожирением с СД2.

Таблица 2. Распределение частот аллелей и генотипов полиморфизма rs1042044 гена GLP-1R

\begin{tabular}{cccccc}
\hline \multirow{2}{*}{$\begin{array}{c}\text { Полиморфизм GLP-1R } \\
\text { Leu260Phe }\end{array}$} & \multicolumn{2}{c}{ Распределение частот генотипов } & \multicolumn{2}{c}{ Распределение частот аллелей } \\
\cline { 2 - 5 } & $\mathbf{C C}$ & $\mathbf{C A}$ & $\mathbf{A A}$ & $\mathbf{C}$ & $\mathbf{A}$ \\
\hline $\begin{array}{c}\text { Контрольная группа, } \\
\text { n=64 }\end{array}$ & $21,90 \%(14)$ & $62,50 \%(40)$ & $15,60 \%(10)$ & $53,1 \%$ & $46,9 \%$ \\
\hline $\begin{array}{c}\text { Больные ожирением } \\
\text { с СД2, n=86 }\end{array}$ & $38,4 \%(33)$ & $45,5 \%(39)$ & $16,3 \%(14)$ & $60,4 \%$ & $39,6 \%$ \\
\hline
\end{tabular}

и GLP-1 натощак и после тестового завтрака ( $r=0,83$, $r=0,83 ; p<0,01$ ) (рис. 2).

Далее был исследован уровень изучаемых метаболитов в зависимости от генотипа полиморфизма rs1042044 гена GLP-1R. Распределение частот аллелей и генотипов полиморфизма rs1042044 гена GLP-1R представлено в табл. 2.

В нашем исследовании в группе больных ожирением с СД2 носителей генотипа СС и СА отмечено увеличение постпрандиального уровня инсулина до 3048 [1978; 4972] и 1462 [1146;2304] нг/мл соответственно ( $<<0,05)$ относительно его содержания натощак. При этом установлено постпрандиальное повышение уровней С-пептида до 3,25 [1,83;4,16] нг/мл и инсулина до 3048 [1978;4972] нг/мл - почти в 2 раза у носителей генотипа CC (Leu/ Leu) по сравнению с таковыми у носителей генотипа CA (Leu/Phe) в группе больных ожирением с СД2 $(p<0,05)$ (табл. 3).

Изучение постпрандиального уровня грелина у больных СД2 выявило его повышение у носителей генотипа CA полиморфизма Leu260Phe гена GLP-1R до 118 $[96,1 ; 157]$ нг/мл по сравнению с таковым у носителей генотипа АА 98 [86;109] нг/мл $(p<0,05)$.

\section{ОБСУЖДЕНИЕ}

\section{Резюме основного результата исследования}

Выявлено нарушение постпрандиальной продукции GLP-1 и грелина у больных ожирением с СД2 после тестового завтрака. В группе больных ожирением с СД2 с генотипом CA (Leu/Phe) отмечена нормальная постпрандиальная динамика уровня инсулина, в отличие от носителей других генотипов полиморфизма Leu260Phe гена
$G L P-1 R$ : постпрандиальное повышение уровня инсулина по сравнению с таковым натощак $(p<0,05)$. У больных ожирением с СД2, носителей генотипа CC (Leu/Leu), установлено постпрандиальное повышение уровней C-пептида 3,25 [1,83;4,16] нг/мл и инсулина 3048 [1978;4972] нг/ мл по сравнению с носителями генотипа CA (Leu/Phe).

Обсуждение основного результата исследования

Несмотря на повышение постпрандиальных уровней С-пептида и инсулина по сравнению с таковыми натощак, постпрандиальное содержание GLP-1 в плазме крови у больных ожирением с СД2 не изменялось в сравнении с его уровнем натощак. Данный факт может указывать на нарушение у больных ожирением с СД2 продукции инкретина, стимулированной поступлением питательных веществ.

Инкретины и грелин взаимосвязаны с энергетическим метаболизмом организма и регуляцией потребления пищи [11]. Продукция грелина достигает максимума незадолго до привычного времени приема пищи, тогда как GLP-1 секретируется после приема питательных веществ [12]. У больных ожирением с СД2 постпрандиальная динамика изучаемых показателей была иной: не было выявлено значимых отличий между уровнями грелина и GLP-1 натощак и постпрандиальными. Сильные положительные корреляционные взаимосвязи между уровнями грелина и GLP-1 натощак и постпрандиальными в плазме крови могут свидетельствовать о нарушении реципрокных взаимоотношений между данными аналитами при СД2.

Другими авторами выявлено ухудшение углеводного обмена при инфузионном введении грелина у здоровых пациентов [13]. Комбинированное введение грелина и антагониста рецептора GLP-1 эксендина (9-39) 
Таблица 3. Уровень гормонов желудочно-кишечного тракта в исследуемых группах в зависимости от варианта полиморфизма Leu260Phe гена GLP-1R.

\begin{tabular}{|c|c|c|c|c|c|c|}
\hline \multicolumn{7}{|c|}{ Уровень С-пептида в плазме, нг/мл } \\
\hline \multirow{3}{*}{ Генотип } & \multicolumn{3}{|c|}{ Натощак } & \multicolumn{3}{|c|}{ После завтрака } \\
\hline & CC & CA & AA & CC & $C A$ & AA \\
\hline & 1 & 2 & 3 & 4 & 5 & 6 \\
\hline $\begin{array}{l}\text { Здоровые доноры } \\
(\mathrm{n}=64)\end{array}$ & $0,81[0,79 ; 0,86]$ & $0,88[0,74 ; 1,14]$ & $0,67[0,66 ; 0,68]$ & $1,67[1,55 ; 2,45]$ & $1,42[0,85 ; 2,15]$ & $1,03[0,86 ; 1,2]$ \\
\hline $\begin{array}{l}\text { Больные } \\
\text { ожирением с СД2 } \\
(n=86)\end{array}$ & $2,180[1,66 ; 2,85]$ & $1,59[1,23 ; 2,36]$ & $1,21[0,87 ; 2,36]$ & $3,25[1,83 ; 4,16]$ & $\begin{array}{c}2,21[1,8 ; 2,49] \\
p_{4-5}=0,049^{*}\end{array}$ & $1,4[1,005 ; 1,79]$ \\
\hline
\end{tabular}

\begin{tabular}{|c|c|c|c|c|c|c|}
\hline \multicolumn{7}{|c|}{ Уровень инсулина в плазме, нг/мл } \\
\hline \multirow{3}{*}{ Генотип } & \multicolumn{3}{|c|}{ Натощак } & \multicolumn{3}{|c|}{ После завтрака } \\
\hline & $\mathrm{CC}$ & CA & AA & $\mathrm{CC}$ & CA & AA \\
\hline & 1 & 2 & 3 & 4 & 5 & 6 \\
\hline $\begin{array}{l}\text { Здоровые доноры } \\
(\mathrm{n}=64)\end{array}$ & $592[584 ; 631]$ & $477[417 ; 657]$ & $460[392 ; 528]$ & $\begin{array}{c}1418 \\
{[1116 ; 1688]}\end{array}$ & $482[473 ; 776]$ & $530[449 ; 611]$ \\
\hline $\begin{array}{l}\text { Больные } \\
\text { ожирением с СД2 } \\
\text { (n=86) }\end{array}$ & $\begin{array}{c}1813 \\
{[985 ; 2246]}\end{array}$ & $\begin{array}{c}1064 \\
{[608 ; 1716]}\end{array}$ & $\begin{array}{c}1498 \\
{[900 ; 2096]}\end{array}$ & $\begin{array}{c}3048 \\
{[1978 ; 4972]} \\
p_{1-4}=0,003^{*}\end{array}$ & $\begin{array}{c}1462 \\
{[1146 ; 2304]} \\
p_{2-5}=0,047^{*} \\
p_{4-5}=0,01^{*}\end{array}$ & $\begin{array}{c}1951 \\
{[1264 ; 2638]}\end{array}$ \\
\hline
\end{tabular}

Уровень GLP-1 в плазме, нг/мл

\begin{tabular}{|c|c|c|c|c|c|c|}
\hline \multirow{3}{*}{ Генотип } & \multicolumn{3}{|c|}{ Натощак } & \multicolumn{3}{|c|}{ После завтрака } \\
\hline & CC & CA & AA & CC & CA & AA \\
\hline & 1 & 2 & 3 & 4 & 5 & 6 \\
\hline $\begin{array}{l}\text { Здоровые доноры } \\
(n=64)\end{array}$ & $177[170 ; 185]$ & 216 [202;239] & $138[123 ; 154]$ & 305 [302;319] & $248[234 ; 252]$ & 123 \\
\hline $\begin{array}{l}\text { Пациенты с СД2 } \\
(n=86)\end{array}$ & $369[249 ; 405]$ & $388[182 ; 458]$ & $\begin{array}{c}438,5 \\
{[374,2 ; 502]}\end{array}$ & $345[262 ; 430]$ & $388[277 ; 530]$ & $428[405 ; 451]$ \\
\hline \multicolumn{7}{|c|}{ Уровень грелина в плазме (нг/мл) } \\
\hline \multirow{3}{*}{ Генотип } & \multicolumn{3}{|c|}{ Натощак } & \multicolumn{3}{|c|}{ После завтрака } \\
\hline & CC & CA & $\mathrm{AA}$ & $\mathrm{CC}$ & $C A$ & $\mathrm{AA}$ \\
\hline & 1 & 2 & 3 & 4 & 5 & 6 \\
\hline $\begin{array}{l}\text { Здоровые доноры } \\
(\mathrm{n}=64)\end{array}$ & $\begin{array}{c}68,95 \\
{[52,7 ; 94,9]}\end{array}$ & $\begin{array}{c}84,8 \\
{[43,9 ; 122,8]}\end{array}$ & $78,6[49,5 ; 119]$ & $55,5[49,5 ; 61,7]$ & $65,2[50,8 ; 93,3]$ & $66,3[48,1 ; 90]$ \\
\hline $\begin{array}{l}\text { Больные } \\
\text { ожирением с СД2 } \\
(n=86)\end{array}$ & $74,9[55 ; 96,9]$ & $112[85 ; 120]$ & $159[97 ; 222]$ & $74,2[68 ; 95,6]$ & $118[96,1 ; 157]$ & $\begin{array}{l}98[86 ; 109] \\
p_{5-6}=0,01^{*}\end{array}$ \\
\hline
\end{tabular}

Примечание: * - уровень значимости определен при помощи критерия Манна-Уитни для независимых выборок (р<0,05). Данные представлены в виде медианы и интерквартильного размаха Me [Q1;Q3].

приводило к более выраженной постпрандиальной гликемии по сравнению с введением только грелина у здоровых лиц [13]. Данный эффект был обусловлен нарушением функционирования $\beta$-клеток и снижением клиренса глюкозы [13]. В проведенном исследовании у больных ожирением с СД2 базальный уровень GLP-1 был выше, чем в группе условно здоровых доноров. Известно, что GLP-1 нивелирует негативное влияние грелина на толерантность к глюкозе. В связи с вышесказанным, выявленное нами повышение базального уровня GLP-1 у больных ожирением с СД2 может быть обусловлено запуском компенсаторного механизма.

Изменение продукции инсулина и С-пептида у больных ожирением с СД2 с различными генотипами поли- морфизма Leu260Phe гена GLP-1R не зависело от плазменной концентрации GLP-1. Функциональная роль полиморфизма Leu260Phe гена GLP-1R до конца неизвестна, однако несколькими другими авторами указывается его роль в изменении продукции кортизола [10]. Данные, полученные на экспериментальных животных и у человека, демонстрируют выраженные инсулинотропные и антигипергликемические эффекты агонистов GLP-1R [14, 15].

У больных ожирением с СД2 с генотипами CC (Leu/Leu) и CA (Leu/Phe) отмечена нормальная постпрандиальная динамика уровня инсулина. У больных ожирением с СД2 с генотипами CC (Leu/Leu) и CA (Leu/Phe) выявлено постпрандиальное повышение уровня инсулина по сравнению с таковым натощак $(p<0,05)$. У носителей генотипа AA 
полиморфизма Leu260Phe гена GLP-1R не было показано постпрандиального подъема уровня инсулина по сравнению с таковым натощак. При этом у больных ожирением с СД2, носителей генотипа CC (Leu/Leu), установлено повышение постпрандиальных уровней C-пептида и инсулина почти в 2 раза по сравнению с носителями генотипа CA (Leu/Phe).

Таким образом, нами зарегистрированы значительные нарушения функциональной активности GLP-1R у больных ожирением с СД2 - носителей генотипа AA полиморфизма Leu260Phe гена GLP-1R. Существуют данные о снижении функциональной активности инкретиновых рецепторов в $\beta$-клетках поджелудочной железы при гипергликемии [8], что согласуется с результатами проведенного исследования. Многими авторами выявлена утрата инсулинотропного эффекта GLP-1 у пациентов с СД2 посредством нарушения передачи инкретинового сигнала $[16,17]$.

Грелин - гормон голода, его концентрация увеличивается натощак и уменьшается после приема пищи [18]. Данный факт не противоречит результатам исследований, демонстрирующих снижение уровня циркулирующего грелина у больных абдоминальным ожирением и его повышение у пациентов на фоне потери веса [18, 19].

У больных СД2, независимо от генотипа полиморфизмa Leu260Phe гена GLP-1R, постпрандиальный уровень грелина не снижался относительно значений натощак, В отличие от значений контрольной группы. Однако у носителей генотипа CA полиморфизма Leu260Phe гена $G L P-1 R$ в группе больных ожирением с СД2 данный показатель оказался выше по сравнению с носителями генотипа АА и не отличался от такового у пациентов с генотипом СC $(p<0,05)$. Данный факт объясняет нарушение пищевого поведения у больных ожирением - не развивается чувство насыщения после приема пищи.

Расположение полиморфизма Leu260Phe в пределах гена GLP-1R показывает, что он может влиять на даун-регуляцию передачи сигнала от GLP-1 к его рецептору, опосредуя изменения в зрелом транслируемом белке [10]. Таким образом, замена в аминокислотной последовательности лейцина на фенилаланин (Leu260Phe) в гене GLP-1R оказывает эффекты на связывание рецептора с лигандом и тем самым вносит вклад в развитие СД2 при ожирении.

\section{Ограничения исследования}

Ограничением данного исследования является малая численность групп пациентов.

\section{ЗАКЛЮЧЕНИЕ}

У больных ожирением с СД2 с генотипом Leu/Leu (CC) и Leu/Phe (CA) полиморфизма Leu260Phe гена рецептора GLP-1 выявлено повышение постпрандиальных плазменных уровней С-пептида и инсулина, более выраженных при генотипе СС.

У носителей генотипа CA полиморфизма Leu260Phe гена GLP-1R в группе больных ожирением с СД2 регистрируется повышенный уровень грелина по сравнению с таковым у носителей генотипа AA; нарушение реципрокных взаимоотношений между плазменным уровнем грелина и GLP-1 у этой категории пациентов может свидетельствовать об участии этих гормонов в нарушении пищевого поведения.

На основании полученных данных мы предполагаем, что наиболее выраженного эффекта при терапии агонистами GLP-1R можно ожидать у больных СД2 с генотипом Leu/Leu (CC) полиморфизма Leu260Phe гена GLP-1R.

Выявленные в работе особенности параметров углеводного обмена при ожирении и их взаимосвязь с полиморфизмом Leu260Phe гена GLP-1R могут представлять интерес для практического здравоохранения и быть использованы для разработки новых патогенетических подходов к профилактике, диагностике, терапии и мониторингу лечения СД2 при ожирении.

\section{ДОПОЛНИТЕЛЬНАЯ ИНФОРМАЦИЯ}

\section{Источник финансирования}

Исследование выполнено при финансовой поддержке РФФИ В рамках научного проекта 18-015-00084-а; при финансовой поддержке РФФИ и КО в рамках научного проекта № 19-415-393004_p_ мол_а (биохимический анализ) и 19-44-390005_p_а (проточная флюориметрия) и субсидии «Организация проведения научных исследований 20.4986.2019/ВУ» Балтийского федерального университета им. И. Канта.

Конфликт интересов

Авторы декларируют отсутствие явных и потенциальных конфликтов интересов, связанных с публикацией настоящей статьи.

\section{Участие авторов}

Скуратовская Д.А. - анализ полученных данных, написание текста, обработка материалов, генотипирование методом ПЦР; Вульф М.А. формирование баз данных пациентов, анализ антропометрических и биохимических показателей; Кириенкова Е.В. - анализ полученных данных, определение уровня гормонов; Миронюк Н.И. - включение и исключение пациентов, вошедших в исследование, диагностирование наличия сахарного диабета 2 типа; Затолокин П.А. - сбор биоматериала в ходе плановых лапароскопических операций; Литвинова Л.С. анализ полученных данных, написание текста.

\section{СПИСОК ЛИТЕРАТУРЫ | REFERENCES}

1. Taylor R. Type 2 diabetes: etiology and reversibility. Diabetes Care. 2013;36(4):1047-1055. doi: https://doi.org/10.2337/dc12-1805

2. Knebel B, Strassburger K, Szendroedi J, et al. Specific Metabolic Profiles and Their Relationship to Insulin Resistance in Recent-Onset Type 1 and Type 2 Diabetes. J Clin Endocrinol Metab. 2016;101(5):2130-2140. doi: https://doi.org/10.1210/jc.2015-4133

3. Vejrazkova D, Lischkova O, Vankova M, et al. Distinct response of fat and gastrointestinal tissue to glucose in gestational diabetes mellitus and polycystic ovary syndrome. Physiol Res. 2017;66(2):283-292.

4. Garber AJ. Novel incretin-based agents and practical regimens to meet needs and treatment goals of patients with type 2 diabetes mellitus. J Am Osteopath Assoc. 2011;111(7 Suppl 5):S20-30.
5. McIntosh CHS, Widenmaier S, Kim SJ. Glucose-dependent insulinotropic polypeptide (gastric inhibitory polypeptide; GIP). Vitam Horm. 2009;80:409-471 doi: https://doi.org/10.1016/S0083-6729(08)00615-8

6. Girard J. The incretins: from the concept to their use in the treatment of type 2 diabetes. Part A: incretins: concept and physiological functions. Diabetes Metab. 2008;34(6 Pt 1):550-559.

doi: https://doi.org/10.1016/j.diabet.2008.09.001

7. Kim W, Egan JM. The role of incretins in glucose homeostasis and diabetes treatment. Pharmacol Rev. 2008;60(4):470-512. doi: https://doi.org/10.1124/pr.108.000604 
8. Koole C, Savage EE, Christopoulos A, et al. Minireview: Signal bias, allosterism, and polymorphic variation at the GLP-1R: implications for drug discovery. Mol Endocrinol. 2013;27(8):1234-1244. doi: https://doi.org/10.1210/me.2013-1116

9. de Luis DA, Pacheco D, Aller R, Izaola O. Role of the rs6923761 gene variant in glucagon-like peptide 1 receptor gene on cardiovascular risk factors and weight loss after biliopancreatic diversion surgery. Ann Nutr Metab. 2014;65(4):259-263 doi: https://doi.org/10.1159/000365975

10. Sheikh HI, Dougherty LR, Hayden EP, et al. Glucagon-like peptide-1 receptor gene polymorphism (Leu260Phe) is associated with morning cortisol in preschoolers. Prog Neuropsychopharmacol Biol Psychiatry. 2010;34(6):980-983.

doi: https://doi.org/10.1016/j.pnpbp.2010.05.007

11. Zhang X, Li W, Li P, et al. Intraportal infusion of ghrelin could inhibit glucose-stimulated GLP-1 secretion by enteric neural net in Wistar rat. Biomed Res Int. 2014;2014:923564 doi: https://doi.org/10.1155/2014/923564

12. Hong $X$, Zhang $H$, Liang $H$, et al. Exendin-4 decreases ghrelin levels through mTOR signaling. Mol Cell Endocrinol. 2016;437:201-212. doi: https://doi.org/10.1016/j.mce.2016.08.039

13. Page LC, Gastaldelli A, Gray SM, et al. Interaction of GLPand Ghrelin on Glucose Tolerance in Healthy Humans. Diabetes. 2018;67(10):1976-1985. doi: https://doi.org/10.2337/db18-0451
14. Ma X, Lu R, Gu N, et al. Polymorphisms in the Glucagon-Like Peptide 1 Receptor (GLP-1R) Gene Are Associated with the Risk of Coronary Artery Disease in Chinese Han Patients with Type 2 Diabetes Mellitus: A Case-Control Study. J Diabetes Res. 2018;2018:1054192. doi: https://doi.org/10.1155/2018/1054192

15. Lee S, Lee DY. Glucagon-like peptide-1 and glucagon-like peptide-1 receptor agonists in the treatment of type 2 diabetes. Ann Pediatr Endocrinol Metab. 2017;22(1):15-26. doi: https://doi.org/10.6065/apem.2017.22.1.15

16. Puddu A, Sanguineti R, Montecucco F, Viviani GL. Effects of High Glucose Levels and Glycated Serum on GIP Responsiveness in the Pancreatic Beta Cell Line HIT-T15. J Diabetes Res. 2015;2015:326359. doi: https://doi.org/10.1155/2015/326359

17. Nielsen ST, Janum S, Krogh-Madsen R, et al. The incretin effect in critically ill patients: a case-control study. Crit Care. 2015;19:402. doi: https://doi.org/10.1186/s13054-015-1118-z

18. Makris MC, Alexandrou A, Papatsoutsos EG, et al. Ghrelin and Obesity: Identifying Gaps and Dispelling Myths. A Reappraisal. In Vivo. 2017;31(6):1047-1050 doi: https://doi.org/10.21873/invivo.11168

19. Giezenaar $C$, van der Burgh $Y$, Lange $K$, et al. Effects of Substitution, and Adding of Carbohydrate and Fat to Whey-Protein on Energy Intake, Appetite, Gastric Emptying, Glucose, Insulin, Ghrelin, CCK and GLP-1 in Healthy Older Men-A Randomized Controlled Trial. Nutrients. 2018;10(2). doi: https://doi.org/10.3390/nu10020113

\section{ИНФОРМАЦИЯ ОБ АВТОРАХ}

*Литвинова Лариса Сергеевна, д.м.н. [Larisa S. Litvinova, MD, PhD]; адрес: Россия, 236001, Калининград, ул. Гайдара, д. 6 [address: 6 Gaidara street, 236001 Kaliningrad, Russian Federation]; ORCID: https://orcid.org/0000-0001-5231-6910; eLibrary SPIN: 6703-3412; e-mail: Iarisalitvinova@yandex.ru

Скуратовская Дарья Александровна, к.б.н. [Daria A. Skuratovskaia, PhD in Biology];

ORCID: https://orcid.org/0000-0002-8679-1135; eLibrary SPIN: 8708-7851; e-mail: DariaSK@list.ru

Вульф Мария Александровна, к.б.н. [Maria A. Vulf, PhD in Biology];

ORCID: https://orcid.org/ 0000-0002-4989-045X; eLibrary SPIN: 1525-4854; e-mail: mary-jean@yandex.ru

Кириенкова Елена Витальевна, к.б.н. [Elena V. Kirienkova, PhD in Biology];

ORCID: https://orcid.org/0000-0002-5980-3321; eLibrary SPIN: 1872-0084; e-mail: elenamed@list.ru

Миронюк Наталья Ивановна, К.M.н. [Natalia I. Myronyuk, MD, PhD];

ORCID: https://orcid.org/0000-0001-5138-9376; e-mail: myronyuk_ni@mail.ru

Затолокин Павел Анатольевич, к.M.н. [Pavel A. Zatolokin, MD, PhD];

ORCID: https://orcid.org/0000-0002-8631-7361; e-mail: endozapa@gmail.com

\section{ЦИТИРОВАТЬ:}

Скуратовская Д.А., Вульф М.А., Кириенкова Е.В., Миронюк Н.И., Затолокин П.А., Литвинова Л.С. Роль полиморфизма Leu260Phe гена рецептора к инкретину GLP-1 в патогенезе сахарного диабета 2 типа при ожирении // Сахарный диабет. - 2019. — T. 22. — №3. — C. 217-224. doi: 10.14341/DM9974

\section{TO CITE THIS ARTICLE:}

Skuratovskaia DA, Vulf MA, Kirienkova EV, Mironyuk NI, Zatolokin PA, Litvinova LS. The role of LEU260PHE polymorphism of the receptor gene to GLP-1 incretin in the pathogenesis of diabetes type 2 diabetes with obesity. Diabetes Mellitus. 2019;22(3):217-224. doi: 10.14341/DM9974 